\title{
Resistir e Persistir: design de moda ético e desenvolvimento sustentável
}

Resist and Persist: ethical fashion design and sustainable development

\author{
MARTINEZ, Adriana F.; Mestre; Universidade Anhembi Morumbi \\ drimartinez@yahoo.com.br \\ RAMOS, Stephany; Graduanda; Universidade Anhembi Morumbi \\ sr.designetico@gmail.com
}

\begin{abstract}
Resumo
Este artigo tem como propósito apresentar questões sustentáveis nos processos de design de moda com a reutilização (upcycling) de tecidos têxteis a fim de promover uma moda ética e evitar que haja o descarte prematuro e indevido desses materiais nos depósitos de lixo. A partir desse procedimento desenvolvem-se ações que podem fazer a diferença quando colocadas em prática estratégias de projeto e modelos de negócios como a logística reversa que reforçam o desenvolvimento sustentável. A metodologia adotada para trabalhar essas questões é o Design Centrado no Humano com estudos focados no Design Emocional, com o intuito de projetar produtos que vão além de aspectos funcionais.
\end{abstract}

Palavras Chave: design de moda; ética; design emocional; upcycling.

\begin{abstract}
This article aims to present sustainable questions in Fashion Design's process, through textile fabrics upcycling, in order to promote ethical fashion and avoid premature and unreasonable material waste at garbage dumps. From this procedure, it is possible to develop actions which can make a difference when project strategies and business models are put into practice, such as reverse logistics, which entrenches sustainable development. The methodology employed to unfold these matters is Human-Centered Design, focusing studies in Emotional Design, with the intention of projecting goods beyond its functional aspects.
\end{abstract}

Keywords: fashion design; ethic; emotional design; upcycling. 


\section{Moda ética e Desenvolvimento sustentável}

O propósito deste artigo radica em mostrar como é possível uma moda ética por meio de ações socioambientais que passam pela responsabilidade do designer desde a pré-produção até o descarte final do produto. Dessa maneira, as questões aqui apresentadas tratam da importância do desenvolvimento sustentável em seus aspectos social, cultural, ambiental e econômico, na construção de um projeto em design de moda. A discussão acerca do descarte produzido pela indústria têxtil colabora para evitar que materiais sejam descartados em locais impróprios depois do uso. Ao aplicar a técnica upcycling (reutilização) de resíduos têxteis é plausível desenvolver uma coleção de moda impedindo que o destino final sejam os depósitos de lixo. Trata-se de resistir e persistir como capacidade de estar sempre se renovando para enfrentar os obstáculos com ideias inovadoras.

Com o ritmo acelerado do atual modelo de desenvolvimento de produção aparecem alguns sinais de insustentabilidade como o esgotamento de recursos naturais, poluição ambiental, mãode-obra análoga à escravidão, entre outros. O desenvolvimento sustentável surge para promover uma economia que "Deixa de ser um fim em si mesma para se transformar em uma nova forma de alcançar o bem-estar das pessoas e do meio ambiente" (SALCEDO, 2014, p.13).

O significado de desenvolvimento sustentável foi sistematizado em 1987 no Relatório Brundtland, que recebeu o nome de "Nosso Futuro Comum", nele foi apresentado às nações que o avanço das destruições ambientais e o desequilíbrio climático danificava todos os seres vivos do planeta. O conceito foi definido como o "desenvolvimento que encontra as necessidades atuais sem comprometer a habilidade das futuras gerações de atender suas próprias necessidades" ${ }^{1}$. Outras acepções seguem essa linha de pensamento, entre elas: "Desenvolvimento sustentável é: bastante para todos e para sempre" (SALCEDO, 2014, p.14).

Nessa perspectiva, entender o papel social do designer e sua importância ética é o combustível para a construção de uma sociedade mais justa.

Designers podem e devem ter outro papel, tornando-se, portanto, "parte da solução". Isto é possível porque no "código genético" do design está registrada a ideia de que sua razão de ser deve melhorar a qualidade do mundo. E é a partir deste ponto que devemos recomeçar, repensando qual é a qualidade do mundo que o design, seguindo sua profunda missão ética, deveria promover (MANZINI, 2008, p.15).

Cabe salientar ainda que o Relatório Brundtland abriu caminhos para traçar metas e estudos possibilitando o lançamento da Agenda 21 no evento da Eco-92, quando foi difundido e incentivado o desenvolvimento sustentável "o design também passou a adotar mudanças e assumir o compromisso ético" (MARTINEZ, 2013), portanto, o projeto ao incorporar as ações sustentáveis admite não só a responsabilidade ambiental, como também contribui para a qualidade de vida das populações sem cessar o desenvolvimento econômico. Em outras palavras, no papel do designer está implícito projetar com a finalidade de colaborar com a sociedade contemporânea, visando um futuro melhor.

Para colocar em prática essa incumbência, a sustentabilidade precisa de uma descontinuidade sistêmica dos níveis crescentes de produção e consumo - considerados uma condição natural pela sociedade -, para um movimento que se oriente na redução desses níveis,

\footnotetext{
${ }^{1}$ https://nacoesunidas.org/acao/meio-ambiente/
} 
portanto voltado para uma melhora na qualidade dos ambientes social e natural. Tal descontinuidade pode ocorrer em um longo período de transição e essa mudança implica em um amplo processo de aprendizagem social.

Esta profunda transformação atingirá todas as dimensões do sistema sociotécnico no qual vivemos: a física (fluxos materiais e energéticos), a econômica e institucional (a relação entre os atores sociais) e a ética, estética e cultural (os valores e juízos de qualidade que lhe darão legitimidade social) (MANZINI, 2008, p.19).

Na mesma esteira, encontra-se o designer Dijon de Moraes (2013), ele sustenta que a estética está intimamente relacionada à ética quando entendida como comportamento coletivo social. Pode-se dizer que nesse novo modelo estético em prol da sustentabilidade há a necessidade de pesquisar "novos e diferentes tipos de matérias-primas, produzidos com tecnologia de baixo impacto ambiental ou mesmo semiartesanal" (MORAES, 2013, p.39).

O princípio de responsabilidade em relação ao futuro significa "garantir às gerações futuras pelo menos o mesmo espaço ambiental - ou seja, a mesma quantidade e qualidade de recursos ambientais que temos atualmente em nossa disposição" (MANZINI, 2008, p.23). Nessa perspectiva, algumas alternativas podem ser consideradas um novo rumo em direção ao bem-estar da sociedade e a preservação do meio ambiente. Um direcionamento para alcançar esse resultado socioambiental está contido no texto da Agenda $21^{2}$ que destaca: "mais que falar de um desenvolvimento sustentável importa garantir a sustentabilidade da Terra, da vida, da sociedade e da humanidade". É nesse cenário que a ética para os designers de moda deve ser concebida como a responsabilidade das atividades projetuais e suas consequências para preservar a casa comum (planeta Terra) e o futuro compartilhado, a fim de prosperar com o desenvolvimento das diversidades natural e social.

Ao reforçar a responsabilidade ética está implícito considerar não só o meio ambiente, mas também a saúde dos consumidores e a situação de trabalho das pessoas envolvidas na indústria da moda. Nesse caso, "a ênfase recai tanto sobre o aspecto ambiental como sobre o aspecto social" (SALCEDO, 2014, p. 33). A moda ética envolve a preocupação com o porvir e adotar tal premissa pode contribuir para que não sejam comprometidas as condições de vida das demais gerações. Para tal é necessário compreender as atividades econômicas, sociológicas e políticas com o objetivo de colaborar com os problemas sociais, já que o design aborda mudanças com o intuito de proporcionar qualidade de vida.

Dentro desse panorama, as propostas projetuais em Design de Moda devem agenciar ações sustentáveis para estimular uma moda ética. Uma das alternativas é reutilização de resíduos têxteis no modelo da logística reversa, atingindo-se assim os pilares do desenvolvimento sustentável e o compromisso ético como condição indispensável para gerar melhorias sociais.

\subsection{Reutilização (upcycling) e Logística Reversa}

Alguns princípios fundamentais para iniciar um processo adequado de design podem ser: "Pensar antes de fazer. Considerar os objetivos. Visto que algumas propostas de design são, em si, eticamente inaceitáveis" (MANZINI, 2008, p. 32). Ora, pensar antes de fazer e vislumbrar as consequências possibilita ao designer propor soluções inovadoras à indústria da moda sem prejudicar a biodiversidade, a cultura e o bem-estar da sociedade atual e futura. Dessa maneira,

\footnotetext{
${ }^{2}$ http://www.mma.gov.br/estruturas/agenda21/_arquivos/CadernodeDebates10.pdf
} 
reduzir os processos insustentáveis dentro da cadeia têxtil ajuda a estimular uma indústria pautada pela ética.

A ética relaciona-se com a proteção da história humana atual, porém garantindo boas condições de vida e meio ambiente apropriado aos que virão depois de nós. Nessa perspectiva, agir eticamente requer o entendimento de que a humanidade e os recursos naturais não estão separados, mas devem ser compreendidos em conjunto com o objetivo de dar continuidade à vida.

Por conseguinte, uma opção para reduzir os níveis de insustentabilidade pode ser a reutilização de materiais têxteis já sem valor comercial e que seriam descartados. Esse é um recurso no qual se aproveita a matéria-prima após uso com o objetivo de impedir o refugo em aterros sanitários, visto que a transformação do material não deprecia o meio ambiente e a saúde de quem nele habita. Segundo Fletcher e Grose $(2011$, p.66) "Na ampla categoria de reutilização há vários níveis de atividade; cada um oferece oportunidades diferentes de inovação." Ainda, as autoras afirmam que:

A reutilização, a restauração e a reciclagem interceptam recursos destinados aos aterros sanitários e os conduzem de volta ao processo industrial como matérias-primas. Assim, desaceleram o fluxo linear de materiais ao longo do sistema industrial. A energia e os materiais necessários para reutilização, restauração e reciclagem variam e deram origem a uma hierarquia de estratégias para gerenciar os resíduos (FLETCHER \& GROSE, 2011, p.63).

Com a prática de reduzir, reutilizar e reciclar, também conhecidos como os 3R's da sustentabilidade, é possível desenvolver uma série de ações práticas para ajudar a estabelecer relações harmoniosas entre os consumidores e os ecossistemas. Essa atitude atenua o custo de vida e contribui para o desenvolvimento sustentável nos pilares econômico, ambiental, social e cultural. A reutilização é relevante porque diminui o descarte gerado pelo consumo desenfreado na sociedade contemporânea. Salcedo (2014, p.17), referindo-se ao livro "Os limites do crescimento" de Donella Meadows, afirma que se consomem os "recursos naturais em ritmo mais acelerado que a natureza é capaz de repô-los". Partindo do princípio equivocado de que a natureza está a serviço do homem, o ser humano provoca uma série de efeitos que destrói os ambientes natural, cultural e social da atualidade.

Os resíduos sólidos descartados pela cadeia têxtil contribuem para ampliar esses resultados cada vez mais expressivos, pois "ao longo do ciclo de produção e vida útil de uma peça de vestuário são gerados diversos resíduos sólidos. Além das próprias peças de roupa que em algum momento serão descartadas" (SALCEDO 2014, p. 28). Há anos discute-se a preocupação com os resíduos sólidos, por esse motivo, "a complexidade das atuais demandas ambientais, sociais e econômicas induz a um novo posicionamento dos três níveis de governo, da sociedade civil, e da iniciativa privada" (Ministério do Meio Ambiente do Brasil) ${ }^{3}$.

Os materiais têxteis, em vez de terminarem enterrados no solo dos aterros sanitários, consolidam-se em um forte potencial para novos negócios na área do design de moda. Reutilizar, reduzir e reciclar são estratégias capazes de incorporar ideias de sustentabilidade, que "combinadas com modos diferentes de pensar e agir pode começar a transformar o setor da moda" (FLETCHER; GROSE, 2011, p. 64). Os programas de logística reversa são ações que impulsionam a reutilização com a finalidade de prolongar a vida útil dos produtos.

\footnotetext{
${ }^{3}$ http://www.mma.gov.br/cidades-sustentaveis/residuos-solidos
} 
Considera-se logística reversa a gestão que obriga produtores e fabricantes a aceitar o retorno de um produto para investir em remanufatura, reutilização ou descarte adequado quando o consumidor tiver terminado de usá-lo. A implantação de alguns programas de logística reversa em empresas mostrou como a responsabilidade não só se estende para toda a cadeia de produção, como também abarca o descarte dos produtos (FLETCHER; GROSE, 2011, p.64).

A Política Nacional de Resíduos Sólidos (PNRS) do Ministério do Meio Ambiente no Brasil estabelece, por meio da lei $n=12.305$ e do decreto $n$ 우 7.404, que logística reversa é o

instrumento de desenvolvimento econômico e social caracterizado por um conjunto de ações, procedimentos e meios destinados a viabilizar a coleta e a restituição dos resíduos sólidos ao setor empresarial, para reaproveitamento, em seu ciclo ou em outros ciclos produtivos, ou outra destinação final ambientalmente adequada ${ }^{4}$.

Figura 1: Descarte inadequado de resíduos têxteis em aterros sanitários.

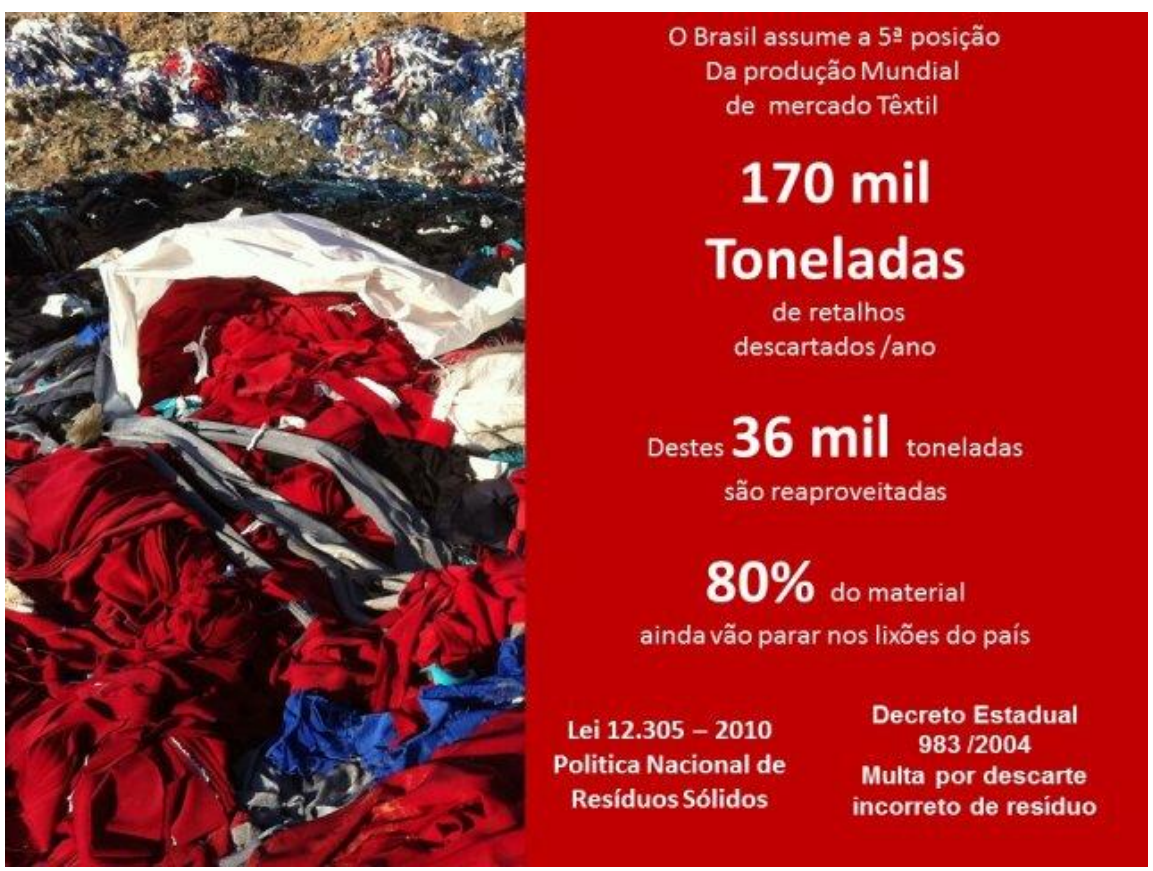

Fonte: Plataforma para inovadores sociais Red Bull Amaphiko.

Dessa maneira, o designer de moda ao utilizar essa estratégia torna-se um agente responsável pelo futuro descarte dos produtos, o que provoca uma mudança total nos sistemas de produção, distribuição e vendas de roupas. Esse novo modelo de organização ajuda a trilhar um caminho de inovações em direção à responsabilidade e suas consequências sustentáveis. A gestão de produtos remanescentes tornou-se uma área promissora para o designer de moda, porque além de apresentar importância ambiental, apresenta também importância econômica, afinal todo resíduo um dia foi comprado e pago como matéria-prima, aproveitar e reaproveitar ao máximo esse material resulta em uma ação inovadora.

\footnotetext{
${ }^{4}$ http://www.mma.gov.br/cidades-sustentaveis/residuos-perigosos/logistica-reversa
} 
Assim, o empreendedorismo precisa ser considerado como um processo de iniciativa capaz de implementar novos negócios. Essa proposição procura identificar problemas e oportunidades adequadas para alavancar mudanças, bem como gerar impactos positivos "de preferência com soluções criativas, inovadoras e sustentáveis" (DORNELAS, 2014, p.2). Pensar um modelo de negócio no qual se possa respeitar a natureza, as condições de trabalho e a ética tornou-se a premissa do mundo atual, principalmente quando se trata do consumo e do descarte produzidos pela indústria têxtil, responsável por ser o segundo setor de consumo atrás apenas do setor de alimentos (SALCEDO, 2014). No presente contexto, o desenvolvimento sustentável emerge como recurso para os problemas vigentes e impulsiona soluções que buscam respeitar o ambiente e a sociedade em que vivemos.

Abordar os impactos ambientais e sociais da atividade de uma empresa implica a analisar os elementos fundamentais de seu modelo de negócio. Tal necessidade proporciona à empresa uma excelente oportunidade de desenvolver práticas inovadoras relacionadas ao design, à produção, e à comercialização de seus produtos (SALCEDO, 2014, p.33).

As práticas de reutilização de materiais têxteis atendem às necessidades da sociedade contemporânea sem comprometer a estética e funcionalidade do produto final. Os modelos de negócios pautados pelos programas de logística reversa possuem vários formatos e pratica o aproveitamento de resíduos, aparas, aviamentos, materiais com defeitos de fábrica e ponta de estoque, inclusive tecidos não utilizados pela indústria de confecção de roupas.

Entretanto, para que todo esse procedimento seja viável é necessário trabalhar com base em uma metodologia projetual apropriada. Indica-se a metodologia do Design Centrado no Humano com estudos focados no Design Emocional relacionado à cidadania, pois promove ações que incentivam fazer o bem ou fazer a coisa certa. Com essa escolha, os produtos vão além dos aspectos funcionais e estéticos, significa pensar em cada etapa do processo e da criação, de modo que as ações decorrentes do projeto também incorporem a reflexão e a emoção.

\subsection{Design Centrado no Humano: Design Emocional}

Por Design Centrado no Humano $(\mathrm{DCH})$ entende-se o método pensado para projetar produtos que têm como foco olhar para o fator humano e social, no qual o processo é mais importante que o produto final. Ao contrário do design centrado no objeto, resultado da era industrial, que desconsidera as qualidades humanas. "A era industrial foi governada pela crença no caráter necessariamente benéfico do progresso tecnológico" (KRIPPENDORFF, 2000, p. 89). Isso significa que até a década de 1980 , os artefatos eram pensados para privilegiar a economia industrial, a expansão dos mercados e o controle cultural. Em suma, os usuários deviam adaptar-se aos produtos desenvolvidos pela indústria e pelos designers.

Essa ação se justifica em decorrência de pesquisas realizadas, nas quais se constatou que o designer desenvolve projetos com o propósito de instaurar futuros melhores e sua finalidade não se limita à produção de objetos materiais. Dijon de Moraes (2013), por exemplo, considera que em um mundo complexo e em constante mutação, são configurados cenários em que preponderam o intangível e o imaterial, e isso exige, segundo ele, uma interação transversal com áreas que explorem mais a subjetividade e menos a objetividade. Aline Haluch (2005) corrobora essa afirmativa ao dizer que "Se o objetivo do design é o homem, o designer deve saber dele muito mais do que medidas e percentis, ele precisa conhecer o homem na sua cultura, seus desejos e sonhos, e suprir necessidades físicas, intelectuais e afetivas". 
Para Norman (2006, p. 15), o "Design apropriado e centrado no humano exige que todas as considerações sejam abordadas desde o princípio, com cada uma das disciplinas relevantes de design trabalhando juntas como uma equipe". Portanto, afirma o autor, trata-se de desenvolver produtos para serem usados por pessoas, de forma que suas necessidades e vontades sejam implantadas no projeto ao longo de todo processo e desde a sua concepção. O objetivo é considerar a importância das relações entre os sujeitos, na medida em que um produto ou serviço pode alterar hábitos e condutas, além de melhorar a sociabilidade, qualidade de vida e bem-estar.

Note-se que o foco foi deslocado para coisas intangíveis, em que se instaura a preocupação com a interpretação de símbolos, significados e preferências dos usuários. Os designers passam a ser agentes operantes de uma metodologia no design que implica as mediações simbólicas com a tarefa de decodificar e reinterpretar o imaginário cultural, para reorganiza-lo no sistema projetual.

Esse ponto de vista considera que "Não reagimos às qualidades físicas das coisas, mas ao que elas significam para nós" (KRIPPENDORF, 2000, p. 89). Dessa forma, pode-se considerar o designer como criador de coisas intangíveis, que transforma seus produtos em práticas sociais, símbolos e preferências, deixando de ser apenas simples objeto. Norman (2006, p. 08) complementa dizendo como "os princípios que norteiam um design de qualidade, centrado no humano, não são relevantes apenas para uma vida mais agradável e prazerosa - eles podem salvar vidas".

O designer como criador de coisas intangíveis pode ressignificar a relação do indivíduo com o produto ao incorporar nos objetos situações memoráveis. Vera Damazio (2013) indica que as memórias são construídas em torno do ambiente social do indivíduo tendo como base suas convenções sociais, valores e meio físico. Além disso, a autora afirma que "todos nós temos coisas que trazem boas recordações e passam a fazer parte de nosso acervo de coisas memoráveis" (DAMAZIO, 2013, p. 44). Revela também como é praticamente impossível separar a conexão entre pessoas, objetos, memória e emoção. Assim, memórias, emoções e sensações são elementos que se relacionam com o design emocional.

Figura 2: Peças de roupas confeccionadas com sobras de tecidos para estofamento podem remeter a aconchego.

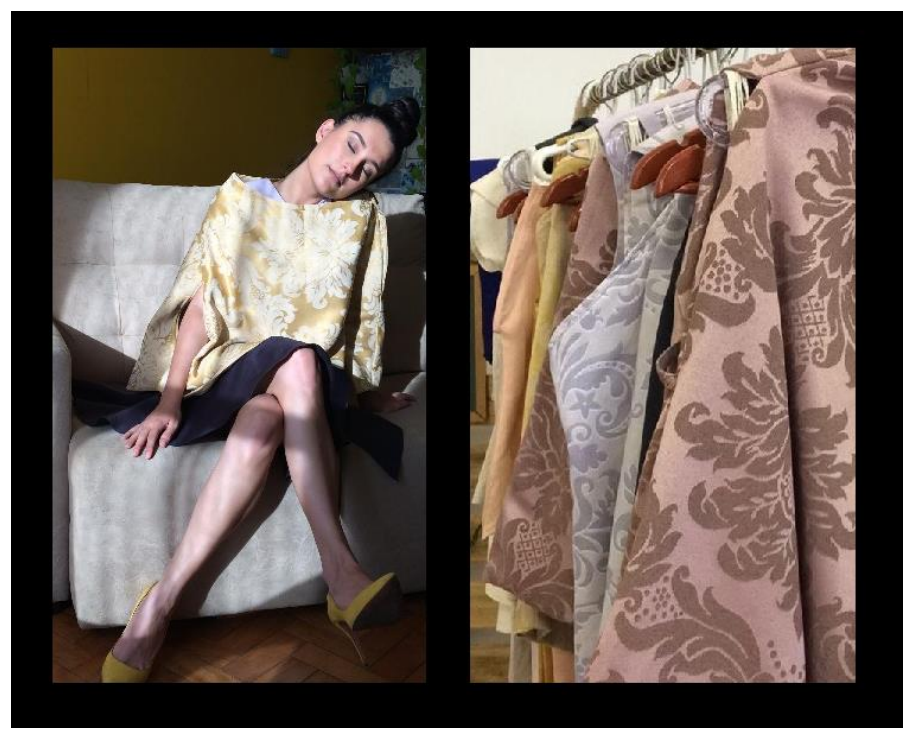

Fonte: Autoria própria. 
O Design Emocional traz o olhar do design voltado para a produção de objetos que impactam positivamente o consumidor-usuário. A emoção varia de pessoa para pessoa e depende da relação experiencial de cada um.

o mundo dos significados dos produtos consiste no papel que estes desempenham na vida de uma pessoa ou de uma comunidade. Está diretamente relacionado às histórias e às memórias evocadas por um produto. Inclui, ainda, os benefícios sociais que um produto pode proporcionar (BUCCINI, 2008, p.08).

Vera Damazio (2013) sustenta que os produtos se tornam memoráveis quando apresentam algumas características com atributos de memorabilidade, como: distinguir o indivíduo (Design e identidade); surpreender e fazer rir (Design e humor); proporcionar conforto e serenidade (Design e bem-estar); criar e fortalecer laços afetivos (Design e sociabilidade); trabalha a autoestima; e incita o fazer bem (Design e cidadania).

Por este motivo, um projeto em design de moda que tenha como objetivo adotar premissas sustentáveis pode selecionar a categoria do design e cidadania para atribuir significados que se preocupem com a ética, boas ações e atitudes responsáveis. O design e a cidadania estão associados à proposta de implantar e promover práticas que encorajem a ética e o vínculo comunitário. Pode despertar sentimentos como comprometimento, capacidades, realização, superação, ou seja, a ação-chave consiste em "estimular a civilidade e práticas solidárias, colaborativas, responsáveis socialmente e em prol do bem coletivo" (DAMAZIO, 2013 p. 52).

\section{Reflexões Finais}

O presente artigo mostrou uma possibilidade de inserir no mercado de moda produtos decorrentes de projetos pautados na ética e no desenvolvimento sustentável. Percebe-se como no âmbito do design de moda iniciou-se um processo que não se fixa apenas na promoção de recursos técnicos e estéticos de produção, pois isso limitaria a reflexão acerca das questões contemporâneas. Quando se ampliam os campos de pesquisa, nos quais são incorporados os modos de vida das populações, abrem-se probabilidades de compreender o ciclo completo dos produtos.

A premissa fundamental radica em enfrenar os processos que tornam a indústria da moda uma área poluidora e responsável por impactos ambientais, por conseguinte, orientar projetos destinados a promover o desenvolvimento sustentável, não apenas como proposta intelectual do corrente momento histórico, mas como imperativo para colaborar com a sociedade contemporânea.

Para que haja eficácia, o projeto em design de moda precisa ir além das práticas projetuais baseadas em qualidades estéticas e imposições mercadológicas. Torna-se fundamental inserir metodologias como o Design Centrado no Humano, recorrer à utilização de materiais antes desprezados e programar com responsabilidade todo o processo.

Significa também, estar ciente da possibilidade de reduzir o alto consumo de água, usar produtos não poluentes, pensar no descarte de materiais, reciclagem e aproveitamento de resíduos com os quais se alteram os processos industriais anteriores, visando alcançar produtividade com qualidade, criatividade e responsabilidade. Nesse sentido, as pesquisas nos âmbitos cultural, social, econômico e ambiental são de extrema importância.

Essa área de preocupação estendida permite expandir a ótica para além dos resultados 
materiais e projetar para descobrir o que há de alternativas no entorno. A importância consiste em refletir sobre a responsabilidade do designer perante a sociedade. Ao estar atento para essas questões, as considerações são dirigidas às atitudes éticas como norteadoras, pois a consequência do processo criativo pode direta ou indiretamente atingir o cenário socioambiental. Essa preocupação torna-se indispensável para apresentar soluções permeadas de análises críticas e experimentações inovadoras.

Dessa maneira, evidencia-se o valor do designer que, inserido em sua realidade particular, é capaz de reconhecer o comprometimento do seu saber. Assim, a condução dos projetos precisa mostrar como sua atuação é a de criar meios para que os produtos sejam inseridos no mercado de maneira correta - cuja responsabilidade deve estar ancorada desde a criação até o descarte.

Refletir o design de moda na atualidade sugere mostrar a viabilidade de usar recursos capazes de conter disposições sociais, culturais, ambientais e econômicas. Portanto, torna-se relevante reforçar que a equação moda e sustentabilidade não se limita ao cuidado ambiental, mas se expande por todas as etapas do processo. Quando se considera o designer de moda como um agente capaz de promover mudanças efetivas na sociedade, o próprio designer se surpreende com suas materializações e se sente edificar um futuro mais exequível.

\section{Referências}

BUCCINI, Marcos. Introdução ao design experiencial. Recife: Edição do autor, 2008. (https://www.academia.edu/8005778/Introdu\%C3\%A7\%C3\%A3o_ao_Design_Experiencial).

DAMAZIO, Vera. Design, memória e emoção: uma investigação para o projeto de produtos memoráveis. In: Cadernos de Estudos Avançados em Design: Design e Emoção / Organização: Dijon de Moraes; Regina Álvares Dias, 2013. Barbacena: EdUEMG. (https://goo.gl/EFt8xb).

DORNELAS, José. Empreendedorismo para visionários: desenvolvendo negócios inovadores para um mundo em transformação. Rio de janeiro: Ed. Empreende/LTC, 2014.

FLETCHER, K.; GROSE, L. Moda \& sustentabilidade: design para mudança. São Paulo: Editora Senac, 2011.

HALUCH, Aline. Pesquisa histórica em design essencialmente interdisciplinar. In: designbrasil, 2005. (http://www.designbrasil.org.br/entre-aspas/pesquisa-historica-em-design-essencialmenteinterdisciplinar/\#.Vgcz1ctdF9C).

KRIPPENDORFF, Klaus. Design centrado no humano: uma necessidade cultural. In: Periódicos Anhembi Morumbi, 2000 (http://periodicos.anhembi.br/arquivos/Hemeroteca/Periodicos_MO/Estudos_em_Design/10717 0.pdf).

MANZINI, Ezio. Design para inovação social e sustentabilidade. Rio de Janeiro: E-papers Serviços editoriais Ltda, 2008.

MARTINEZ, Adriana F de. Design de moda e sustentabilidade. In: 9o Colóquio de Moda, 6a Edição Internacional, Eixo 8, 2013. (http://www.coloquiomoda.com.br/anais_ant/anais/9-Coloquio-deModa_2013/COMUNICACAO-ORAL/EIXO-8-SUSTENTABILIDADE_COMUNICACAO-ORAL/Design-deModa-e-Sustentabilidade.pdf).

MINISTÉRIO do MEIO AMBIENTE. Ética e sustentabilidade. In: Caderno de debate, Agenda 21 e 
sustentabilidade. Secretaria de Políticas para o Desenvolvimento Sustentável, 2006. (http://www.mma.gov.br/estruturas/agenda21/_arquivos/CadernodeDebates10.pdf).

Logística reversa. In: Cidades Sustentáveis, Resíduos Perigosos,

(n/d) (http://www.mma.gov.br/cidades-sustentaveis/residuos-perigosos/logistica-reversa).

. Resíduos sólidos. In: Cidades Sustentáveis, Resíduos Sólidos,

n.d. (http://www.mma.gov.br/cidades-sustentaveis/residuos-solidos).

MORAES, Dijon de. Metaprojeto como modelo projetual. In: Cadernos de Estudos Avançados em Design, 2013. Barbacena, MG: EdUEMG. (https://goo.gl/e2d5Vn).

NAÇÕES UNIDAS no BRASIL (ONUBR). A ONU e o meio ambiente. In: Meio Ambiente, (n.d). (https://nacoesunidas.org/acao/meio-ambiente/).

NORMAN, Donald A. O design do dia-a-dia. Rio de Janeiro: Rocco, 2006.

SALCEDO, Elena. Moda ética para um futuro sustentável. Barcelona: Ed. GG moda, 2014. 